\title{
Climbing Robot for Ferromagnetic Surfaces with Dynamic Adjustment of the Adhesion System
}

\author{
Manuel F. Silva, ${ }^{1,2}$ Ramiro S. Barbosa, ${ }^{1,2}$ and António L. C. Oliveira ${ }^{2}$ \\ ${ }^{1}$ GECAD Knowledge Engineering and Decision Support Research Center, Rua Dr. António Bernardino de Almeida, \\ 4200-072 Porto, Portugal \\ ${ }^{2}$ Department of Electrical Engineering, Institute of Engineering-Polytechnic of Porto (ISEP/IPP), Dr. António Bernardino de Almeida \\ Street, 4200-072 Porto, Portugal \\ Correspondence should be addressed to Manuel F. Silva, mss@isep.ipp.pt
}

Received 14 September 2011; Revised 21 December 2011; Accepted 25 December 2011

Academic Editor: Danica Kragic

Copyright ( $) 2012$ Manuel F. Silva et al. This is an open access article distributed under the Creative Commons Attribution License, which permits unrestricted use, distribution, and reproduction in any medium, provided the original work is properly cited.

This paper presents a climbing robot with wheeled locomotion and adhesion through permanent magnets, developed with the intention of being used in the inspection of different types of man-made ferromagnetic structures, such as towers for wind turbines, fuel storage tanks, and ship hulls. In this paper are presented the main considerations thought for its project, as well as several constructive aspects, among which are detailed its mechanical and electrical construction, the implemented control architecture, and the human-machine interface developed for the manual and automatic control of the vehicle while in operation. Although it can be manually controlled, the vehicle is designed to have a semiautonomous behavior, allowing a remote inspection process controlled by a technician, this way reducing the risks associated with the human inspection of tall structures and ATEX places. The distinguishing characteristic of this robot is its dynamic adjustment system of the permanent magnets in order to assure the machine adhesion to the surfaces, even when crossing slightly irregular and curved surfaces with a large radius.

\section{Introduction}

The interest in the development of climbing robots has grown rapidly in recent years. Climbing robots are useful devices that can be adopted in a variety of applications such as maintenance, building, inspection, and safety, mainly in the process and construction industries. These systems are mainly adopted in places where direct access by a human operator is very expensive, because of the need for scaffolding or special structures, or very dangerous, due to the presence of an hostile environment. The main motivations for its use are to increase the operation efficiency, by eliminating the costly assembly of scaffolding, or to protect human health and safety in hazardous tasks. Several climbing robots have already been developed, and others are under development, for applications ranging from cleaning to inspection of difficult to reach constructions [1].

A wall-climbing robot should not only be light, so that it may reduce excessive adhesion forces, but also have large payload in order to carry instrumentations and ancillary equipment, for the tasks it is designed, during navigation. These machines should be capable of travelling over different types of surfaces, with different inclinations, such as floors, walls, ceilings, and to walk between such surfaces [2-5]. Furthermore, they should be able of adapting and reconfiguring for various environment conditions and to be self-contained.

In recent decades, there have been many applications envisioned for these robots, especially in the areas of cleaning, inspection, maintenance, or troubleshooting of hazardous environments, or on the exterior of tall buildings and other human constructions $[2,6,7]$.

Finally, its application has also been proposed in the areas of assistance to humans [8] and prevention measures and fire fighting $[9,10]$.

Up to now, considerable research has been devoted to these machines and various types of experimental models have already been proposed-according to Chen et al. [10], 
more than 200 prototypes aimed at such applications have been developed worldwide by the year 2006 .

However, it is worth noting that the practical application of climbing robots, out of the laboratory environment, is still limited [2]. Excluding a small number of successful industrial products $[11,12]$, most are just prototypes, and few of them can be found in current use, due to their poor performance during on-site testing (regarding aspects such as its speed, cost, and reliability). Chen et al. [10] presents the main project issues affecting the performance of climbing robot systems and suggests possible solutions to the identified problems.

The major two issues involved in the conception and design of wall climbing robots are their locomotion and adhesion methods [1].

The following described organization of the climbing robots, according to their methods of locomotion and adhesion to surfaces, is not consensual. There are other authors who classify the methods of locomotion and adhesion to the surfaces of these machines according to other categories [7, 13-15].

With respect to the locomotion type, three types are often considered: robots that use sliding segments for locomotion (the frame walking), those that move using wheels and those using legs for locomotion. Robots that make use of sliding segments are capable of moving relatively fast, but are not suitable to be applied in very irregular surfaces. Wheeled robots can move only on surfaces with small irregularities, moving at relatively high speeds. On the other hand, robots with legs easily handle the obstacles encountered in the environment, while its speed is usually smaller and require complex control systems.

Regarding the adhesion to the surface, climbing robots should be able to produce a secure gripping force, to ensure that the vehicle moves safely, using a light-weight mechanism. According to the adhesion method, these robots are generally classified into four groups: vacuum or suction cups, magnetic, gripping to the surface, and propulsion type. Recently, new methods for assuring the adhesion, based on biological findings, have been proposed.

The principle of adhesion based on the creation of a depression or vacuum presents as its main characteristics the fact that involved mechanisms are lightweight and easy to control, although it presents the problem of compressed air supply. An alternative, with costs in terms of weight, is the adoption of a vacuum pump. Adherence based on the principles of magnetism involves heavy actuators and can only be used on ferromagnetic surfaces. The use of gripping to the surface for the purpose of adherence implies that the surfaces in which these robots move exhibit characteristics that facilitate their gripping. Robots that use propulsion forces make use of thrust forces developed by propellers to adhere to surfaces, but are used in very limited and specific applications, mainly in submerged environments.

Among the drawbacks of the adhesion based on magnets, one can mention the fact that if the surface is very thin, it can deform and bend. In the limit situation, the surface can enter in contact with the permanent magnets, this way making

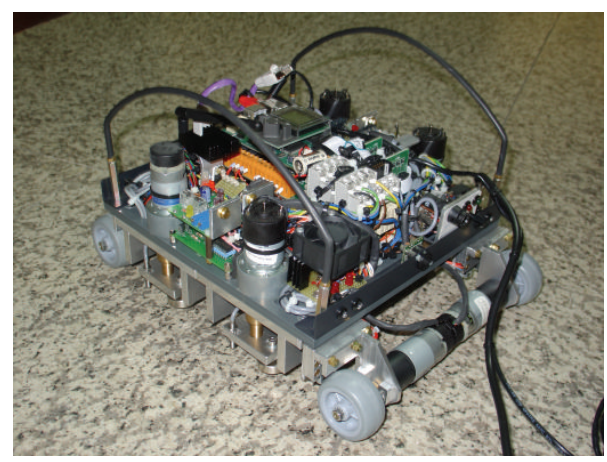

FIGURe 1: Photo of the final prototype of the developed climbing robot with locomotion through wheels and adhesion with permanent magnets.

difficult the locomotion of the robot. Another problem that can arise with this technology is associated with the fact that the surface can present irregularities. These irregularities can make the permanent magnets very close to the surface, even causing their contact, leading to the manifestation of an increased friction; the opposite situation can also occur, that is, an exaggerated clearance, which might jeopardize the ability of the robot to adhere to the surface where it is moving, that could even lead to his downfall.

To overcome this problem, in the machine presented in this paper (see Figure 1), is implemented a device to vary the distance between the magnets and the surface where the robot moves, depending on the dimensions of the irregularities detected by the robot itself, in order to maintain this distance constant and controlled. Thus, we propose a robot with permanent magnets, which are dynamically adjusted to the surface of displacement, through the adoption of a system to detect the magnets distance from the surface, using two inductive sensors combined with a support structure coupled to an actuated worm shaft.

Keeping these ideas in mind, the sequel of this paper is organized as follows. Section 2 presents a brief state of the art concerning climbing robots using magnetic adhesion and adopting wheels for locomotion. Section 3 presents the main design considerations taken into account when designing the robot. Based on these design considerations, Section 4 introduces the mechanical structure of the robot and Section 5 its control architecture. Based on the implemented electronics, in Section 6 is presented the programming architecture for the vehicle and, in Section 7 the HumanMachine Interface developed for the manual and automatic control of the climbing robot. In Section 8 are presented and discussed several experimental results obtained while testing the prototype. Finally, in Section 9 are presented the main conclusions of the work.

\section{State of the Art}

This section analyzes the main characteristics and technological aspects of climbing robots adopting locomotion through wheels and adhesion based on magnetic actuators. 
2.1. Wheeled Locomotion. A common form of locomotion for climbing machines is the adoption of wheels $[3,5,13,16-$ 25]. These robots can easily achieve relatively high speeds, when compared with vehicles that use other strategies to implement the locomotion, but have limitations in transposing obstacles.

It is frequent, in this case, the adoption of permanent magnets or the suction force to ensure the vehicle adherence to the surface of displacement. In more rare cases, there are robots that move on wheels but who grab to the displacement surface to ensure the adherence [26].

In the case of using wheels to implement the locomotion, often the vehicle only presents a two-wheel drive and a passive wheel, in a tricycle structure $[7,17,19,25,27]$ since the use of vehicles with four or more wheels implies the adoption of a damping system that ensures that the wheels are always in contact with the surface, even if it presents irregularities [7].

However, on some wheeled robots that use permanent magnets for adhesion to the surface, there are problems and control difficulties. If the surface is not flat or shows irregularities, the distance change between the permanent magnets and the surface of adhesion leads to the variation of the magnetic adhesion force. This variation can, in the worst situation, be insufficient to ensure the robot adherence to the surface, causing it to become detached; on the other extreme, it can cause the magnets contact with the surface, dramatically increasing the friction force, and hindering the movement of the vehicle $[17,20]$.

In the case of wheeled robots that use the suction force for adhesion to the surface, there are also control difficulties. These vehicles need to maintain a spacing between the surface where they are moving and the base of the robot. This technique can create problems, both with the loss of pressure, or with the increased friction with the surface, especially if the spacing is too small, or if some material is used to minimize the pressure leakage.

To overcome the limitation that these vehicles present in the transposition of obstacles, Longo and Muscato [19] developed a modular robot, which they called Alicia ${ }^{3}$ based on the Alicia II robot with wheeled locomotion. This system results from the junction of three Alicia II modules, through two links with joints at their ends, which are actuated by two pneumatic cylinders. In the absence of obstacles the system moves using all the wheels, meaning that all Alicia II modules are in contact with the surface. When a barrier or an obstacle, with a height greater than $1 \mathrm{~cm}$, is detected in the path of the vehicle, the system removes the Alicia II modules of the surface, one by one, in order to surmount the obstacle by moving the corresponding links to each end module. To separate the central module, the system moves the two links simultaneously. Additionally, each of the modules can perform a rotation in relation to the links between them, so as to allow the movement in any direction.

2.2. Magnetic Adhesion. The most important task in the design and development of a climbing robot is to develop an appropriate mechanism to ensure that the robot adheres to different types of walls and/or surfaces reliably without sacrificing its mobility.

Magnetic adhesion is a principle adopted for the creation of an adhesion force, in specific cases where the surface allows it. Magnetic adhesion can be highly desirable due to its inherent reliability. This method is fast but, depending on the final weight of the robot, may involve the use of heavy actuators to obtain the required adhesion force. Nevertheless, the magnetic adhesion is only useful in specific environments where the surface is ferromagnetic and, thus, represents an unsuitable option for most applications.

One possibility is the use of electromagnets [28-30]. Another possibility is the use of permanent magnets for assuring the robot adhesion to surfaces, combined with the use of wheels $[17,18,25]$ (as in this case) or tracks to move $[16,31]$. The main advantages of the solution with permanent magnets is that there is no need to spend energy in the adhesion process, the robot does not experience any loss of adhesion in the case of a power failure and the fact that permanent magnets are suitable for application in hazardous environments, such as the ATEX zones associated with flammable products stored in warehouses or tanks $[18,27]$.

The main problem that can arise with this technology, relates to the minimum thickness of the surface on which the robot moves. If the thickness of the surface is too small, it can deflect and come into contact with the magnets. This leads to a large increase of the frictional force between the vehicle and the displacement surface preventing, in the limit situation, the motion of the robot. To overcome this problem, Akinfiev and Armada [17] suggest using a device to vary the distance (and the relative slope, if necessary) between the magnets and the displacement surface, according to the shape and dimensions of the irregularities detected by the robot, in order to maintain this distance approximately constant. This is the type of solution adopted in the developed prototype, although with major constructive differences.

A third solution is to use wheels or tracks equipped with permanent magnets, spaced at regular intervals over the surface of the wheels or tracks, that allow to implement the locomotion and adhesion at the same time [20, 22, 31, 32].

Permanent magnets are fragile and can break, and can cause marks on the surfaces. Furthermore, its surface is smooth which can lead to slipping of the vehicles during their locomotion. To prevent these situations, Yan et al. [16] covered the permanent magnets with a thin layer of vulcanized rubber to eliminate these potential problems, without great loss of adhesion force strength.

The adoption of permanent magnets makes the robot more reliable and secure, but there is one drawback: it is more difficult to control adhesion and, in particular, the release of the robot from the surfaces in which it must work. To minimize this problem, dedicated equipments to facilitate the removal of the robot from the surfaces in which it moves are sometimes provided [16]. 


\section{Robot Main Design Considerations}

Bearing in mind the above presented state of the art, in the sequel are described the main design considerations followed for the implementation of the climbing robot prototype.

3.1. Intended Applications of the Climbing Robot. The robot described in this paper was developed with the intention of being a first prototype of a vehicle intended to inspect high man-made structures of ferromagnetic materials, such as fuel storage tanks, towers for wind turbines, and ship hulls.

All these structures generally present a smooth surface, without big curvatures and are characterized by the existence of welding cords (or protrusions), in the vast majority of the cases of small height, along the surface.

Given these specifications it was decided to adopt a wheeled robot, with four wheels, and with a sort of a suspension system, to which we refer as the dynamic adjustment of the adhesion system, able to cope with the welding cords.

3.2. Computation of the Magnetic Adhesion Force. In order to choose the adequate permanent magnets for the robot under development, some considerations regarding the weight of the final vehicle were first made.

The main idea was to build a robot adopting a modular structure, being constituted by a rigid PVC base and four equal standard units (each containing a motor and a wheel for locomotion and another motor and a magnet for the adhesion), assembled on it, as will be described in greater detail in the following section. Each of these standard units is composed of an actuated locomotion system composed by a pair of wheels, one in rubber and the other magnetic (that was not considered in the initial phase of the project), and an actuated structure to adjust the permanent magnet distance to the displacement surface.

The weight of each motor, given by the manufacturer is $1.78 \mathrm{~N}$. Since each module possesses two motors, their weight is $3.56 \mathrm{~N}$. Each rubber wheel weights 1.36 N. For the modular metallic structure (developed in steel) we estimated a weight of approximately $5 \mathrm{~N}$, for each unit. Summing up these values, it was considered a weight of $9.92 \mathrm{~N}$ for each module.

On top of this structure was assumed that would be assembled a standard Allen Bradley MicroLogix 1100/1763 Programmable Logic Controller (PLC) weighting $8.3 \mathrm{~N}$, without considering the $\mathrm{I} / \mathrm{O}$ modules. These modules add about $4.9 \mathrm{~N}$ to the vehicle weight.

Furthermore, we predicted the adoption of a few printed circuit boards (PCB), for the implementation of the discrete control of the motors of the vehicle. For all the needed PCB we estimated a weight of $5 \mathrm{~N}$.

Summing all these values, we reach the conclusion that the total estimated weight of the vehicle would be around $57.88 \mathrm{~N}$.

3.3. Selection of the Permanent Magnets. Based on the previously described estimates for the total robot weight, the worst condition was assumed. Under this condition the

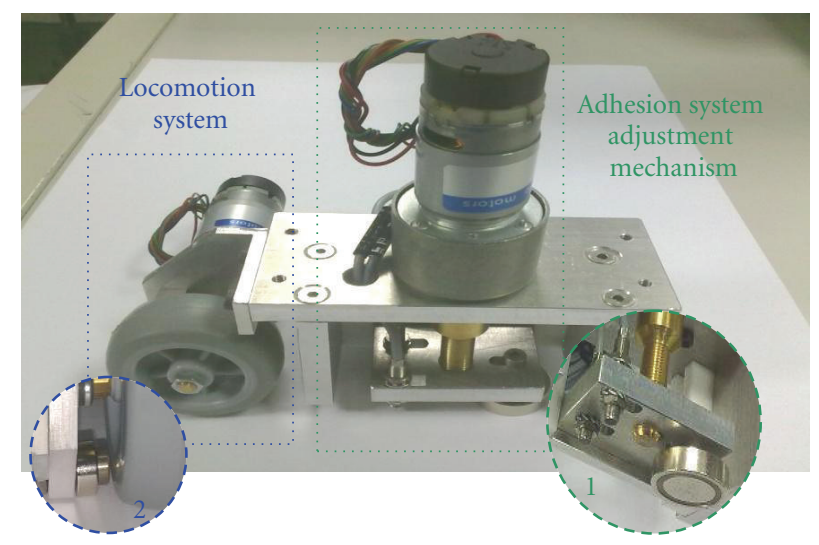

FIGURE 2: Modular standard unit, where it is visible the locomotion system (left) and the adhesion system dynamic adjustment mechanism (right).

robot would need to be supported on the displacement surface upside down. This meant that the four permanent magnets had to develop a force, at least, equal to $57.88 \mathrm{~N}$ (or approximately $15 \mathrm{~N}$ for each magnet).

The magnetic force developed by permanent magnets depends heavily on the following factors: distance between magnet and object (the force decays very rapidly with the distance), material of object of magnetic attraction (there is a loss of $30 \%$ of the magnetic force if the surface where the robot moves is built of construction steel, which is the usual for the applications under consideration), surface area of the object of magnetic attraction, direction of the force and thickness of the object of magnetic attraction.

Given these considerations, was assumed the rather unfavorable situation that on normal robot operating conditions the magnet would only develop approximately $15 \%$ of the maximum possible force. This implies that the maximum achievable force by the permanent magnet would be $100 \mathrm{~N}$.

Looking at the supermagnete manufacturer catalogue permanent magnets characteristics, were chosen supermagnete FTN-20 permanent magnets. Each of these permanent magnets presents a maximum magnetic force of approximately $108 \mathrm{~N}$, under "optimum conditions."

\section{Mechanical Structure}

Based on the robot design considerations, discussed in the Section 3, in the following is described the implementation of the climbing robot prototype.

This robot is built adopting a modular structure, being constituted by a rigid PVC base and four equal standard units (each is a locomotion and adhesion module), assembled on it [33]. Each of these standard units (Figure 2) is composed of an actuated locomotion system composed by a pair of wheels, one in rubber and the other magnetic (Figure 2, lower left corner), and an actuated structure to adjust the permanent magnet distance to the displacement surface (Figure 2, lower right corner).

Each module will be described in detail in Sections 4.1 and 4.2. 


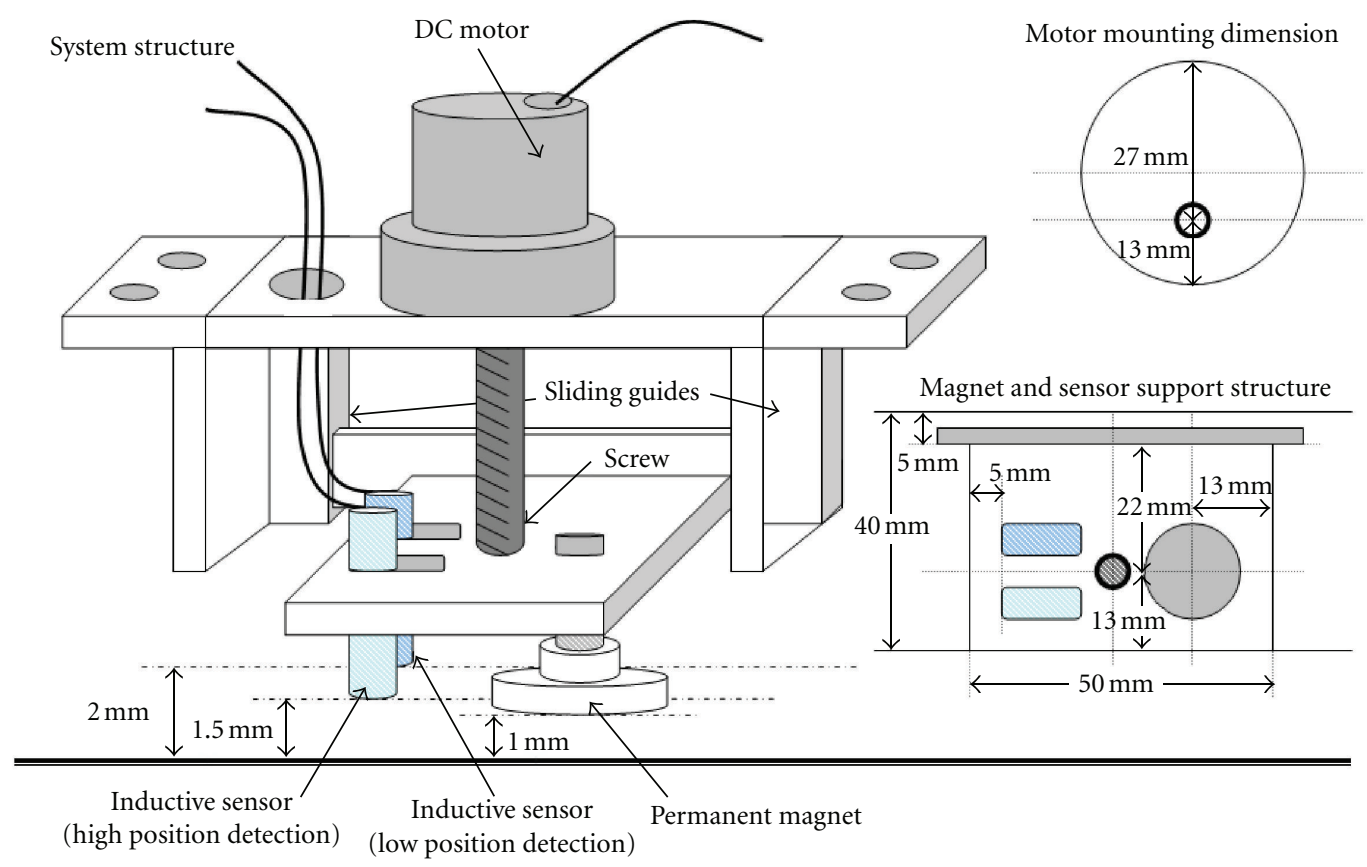

FIGURE 3: Scheme of the system for the dynamic adjustment of the distance between the permanent magnets and the surface of displacement.

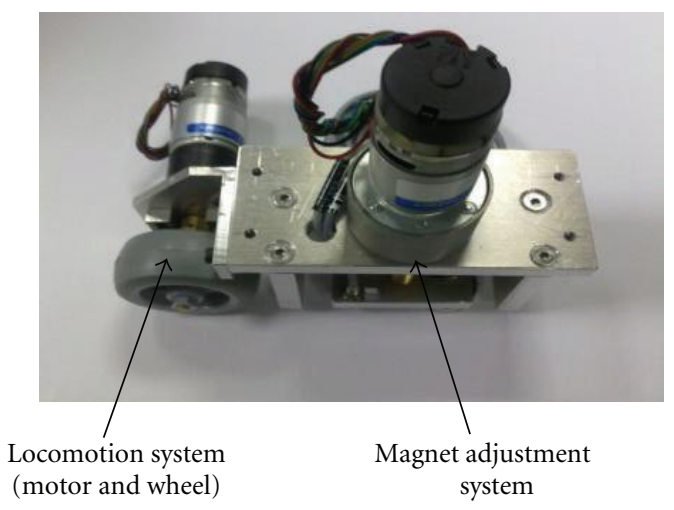

(a)

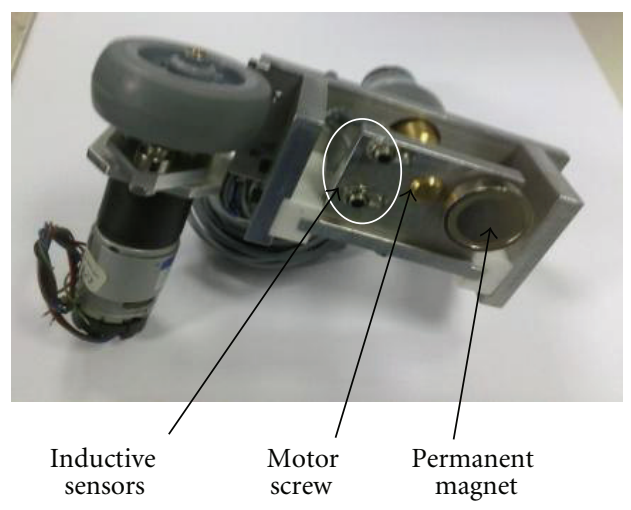

(b)

FIGURE 4: Locomotion system (motor and wheel) and magnet adjustment system (a) and the two inductive sensors, motor screw and magnet (b).

4.1. Adhesion System. The adhesion module is responsible for supporting the robot weight when it is placed in a vertical ferromagnetic surface. This unit is composed by the permanent magnets and by two inductive sensors, responsible for detecting the distance to the locomotion surface.

Figure 3 schematically presents the system for the dynamic adjustment of the distance between the permanent magnets and the surface of displacement. The actuated system is composed by the motor (Gearmotor $12 \mathrm{VDC}$ $33 \mathrm{rpm}$ ) coupled to the support structure, the permanent magnet (supermagnete FTN-20) and the inductive sensors (IFM IY5049). Using the distance information obtained by the two inductive sensors, it dynamically adjusts the magnet distance to the contact and locomotion surface using an actuated worm shaft.

One of the inductive sensors is responsible for detecting the high position (farthest point from the attachment surface) and the other the low position (nearest point from the attachment surface). The permanent magnets dynamic adjustment system can use two distinct modes of reference (in relation to the high or low position detection inductive sensor).

In Figure 4 it is possible to see a photograph of the developed dynamic adjustment system, to keep a constant distance between the permanent magnets and the surface where the robot is moving, in the presence of irregularities. 


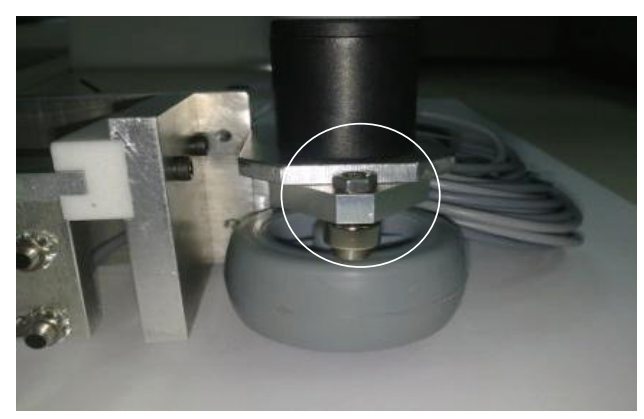

(a)

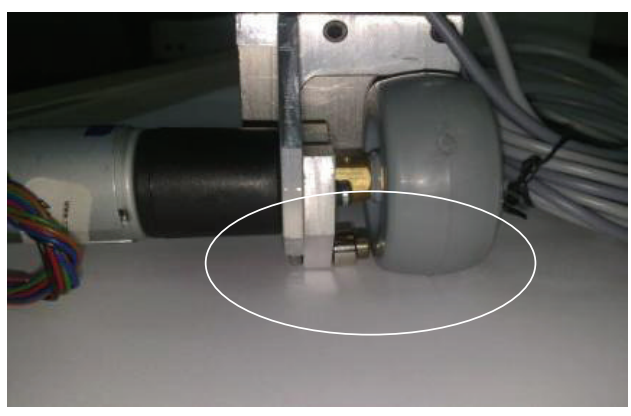

(b)

FIgURE 5: Locomotion system aided with a small rotational circular permanent magnet.

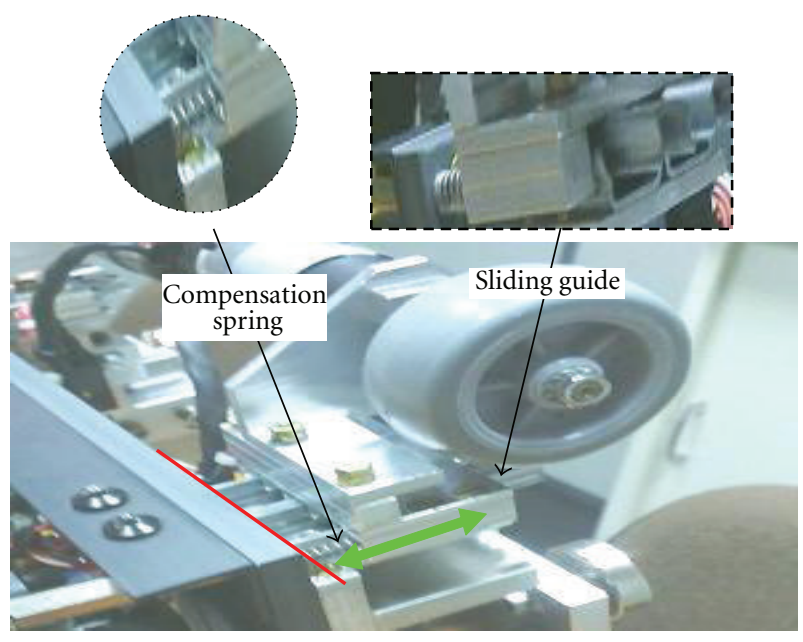

FIGURE 6: Photo of the autolevelling system, with the sliding guide and spring compensated structure.

4.2. Locomotion System. Concerning the locomotion system, each of the four standard units, which is mounted on a set that also contains the magnet vertical adjustment system, consists of a motor (Gearmotor 12 VDC $62 \mathrm{rpm}$ encoder) and a rubber wheel (with a diameter of $50 \mathrm{~mm}$ ) to improve the adhesion to the surface of displacement.

A small circular magnet (with a diameter of $10 \mathrm{~mm}$ ) is assembled in an almost parallel assembly to the outermost part of the wheel, with the possibility of rotation in synchronism with it. Its purpose is to maximize the adherence to the contact surface, allowing the robot to move from a horizontal surface to a vertical one. Figure 5 illustrates this peculiarity of the locomotor system.

An autolevelling structure, composed of a mechanism with a sliding guide and compensated through a spring, was implemented in the two rear modules to assure the total adherence of the four locomotion units to the contact and locomotion surface, even when this surface does not present perfectly flat and regular characteristics, as can be seen in Figure 6.

4.3. Assembly of the Standard Units in the PVC Base. The assembly of the four modules, to give rise to the robot, can be seen in Figure 7, where it is possible to clearly identify the four equal standard units (Figure 7(a)) and the assembled robot standing on a vertical ferromagnetic surface (Figure 7(b)), being also possible to note the standard units and the logical control unit of the machine.

\section{Control Architecture}

The control of this robot is based on a standard Allen Bradley MicroLogix 1100/1763 PLC. The control program adopted for its operation is implemented on the PLC, with the aid of a programming software proprietary of the used PLC (Allen Bradley).

5.1. PLC Inputs/Outputs. According to the manufacturer, this PLC is adequate for remote monitoring and for applications that require high memory space, but it presents a rather limited number of inputs/outputs (I/O). Thus, it was necessary to attach two expansion boards, one with eight digital inputs (1762-IQ8) and another with eight digital relay outputs (1762-OW8).

This way, since the PLC allows the use of 10 inputs, and the expansion module has 8 inputs, there is a total of 18 inputs available for use.

This PLC is limited to the possibility of using only two direct analog inputs. These can be configured to be connected to devices that have voltage output. In this application, these PLC inputs are used to connect the front and rear ultrasonic sensors (also called sonars) used to detect obstacles.

The set of outputs used is obtained directly from the PLC, as well as from the expansion module, which is coupled by a dedicated bus to the PLC. The PLC allows the use of 6 outputs: two using Fast FET, two using FET and two using relays, while the expansion module provides 8 outputs, all of them using relays.

Besides the PLC, there was the need to develop several dedicated PCB to support the adequate control of the system [34]. This electronics is devoted to power the entire system and to its configuration and logical control. Figure 8 presents the schematic implementation of the complete control system. 


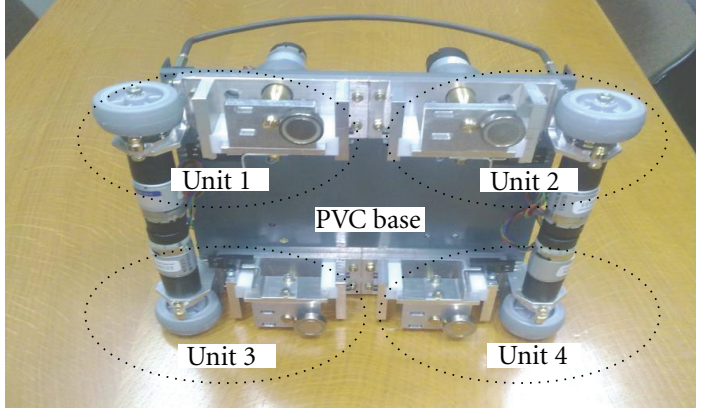

(a)

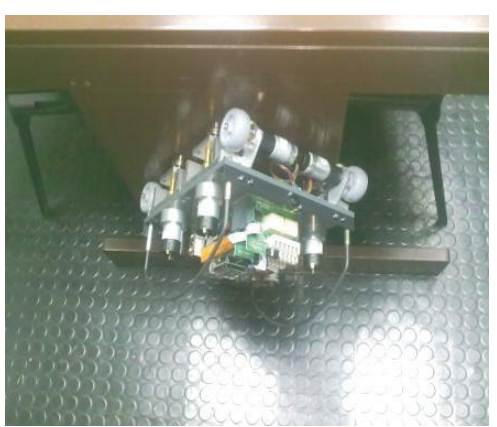

(b)

FIGURE 7: Mechanical structure of the robot, with the four modular standard units assembled on it (a), and view of the assembled robot (without the electronics) standing on a vertical ferromagnetic surface (b).

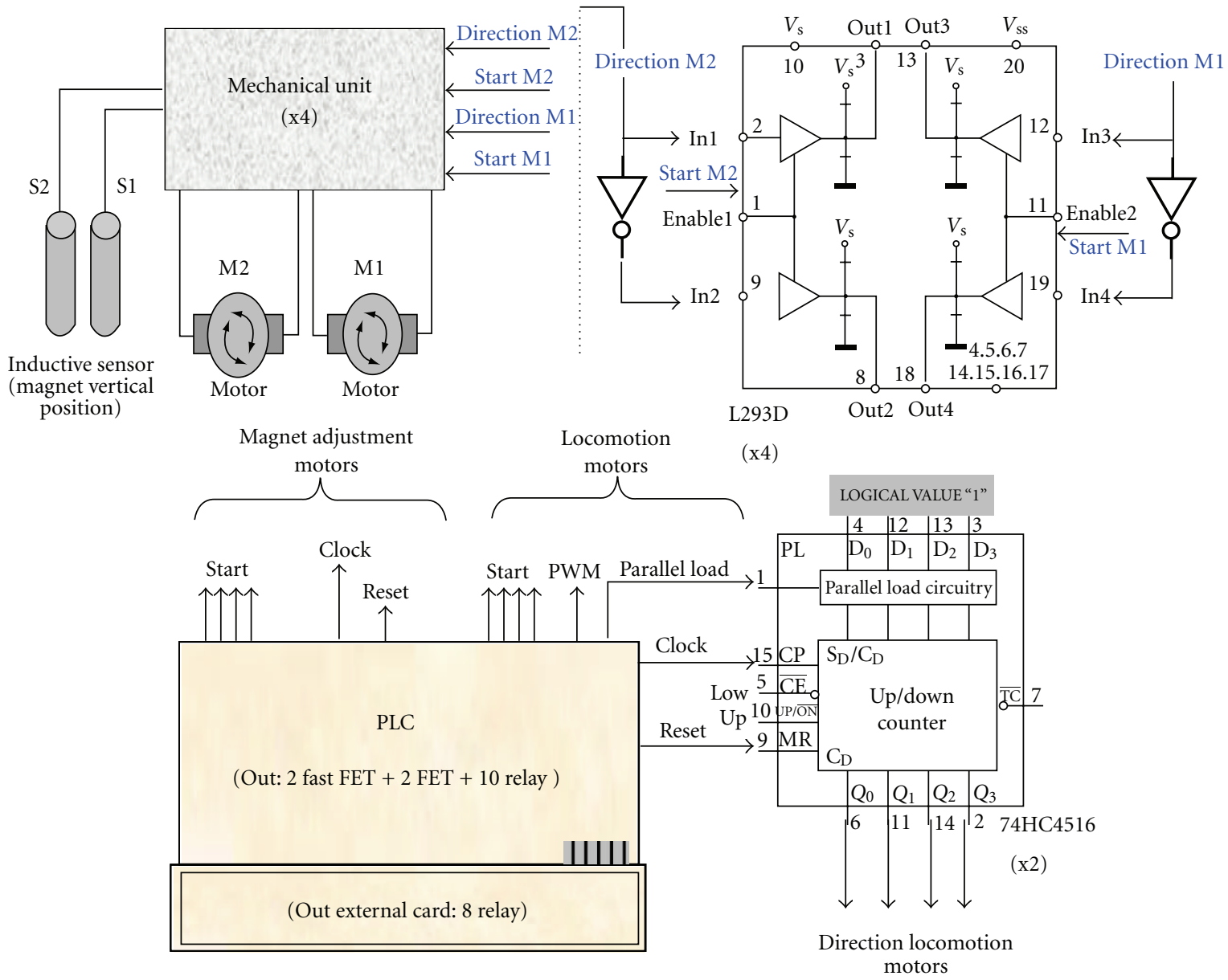

FIGURE 8: Schematic implementation of the climbing robot control architecture.

It is possible to identify in the diagram of Figure 8 the implementation of a set of logic circuits, allowing the optimal use of the scarce I/O resources available in the PLC.

5.2. Logical Circuits. Both the Adhesion Unit and the Locomotion Unit are associated with a logic circuit that allows its optimized control by the PLC [34].
In the case of the Adhesion Unit control logic electronic circuit, its working principle is based on a binary up/down counter (74HCT4516 IC), aided by logical inverters and Quad Push-Pull Drivers. The Quad Push-Pull Drivers, of the L293D type, serve to drive the four motors, with a voltage of $12 \mathrm{~V}$ DC. In each L293D are combined the four half-H drivers to form two $\mathrm{H}$ bridges, which drive two motors (both on the same side of the climbing robot). 


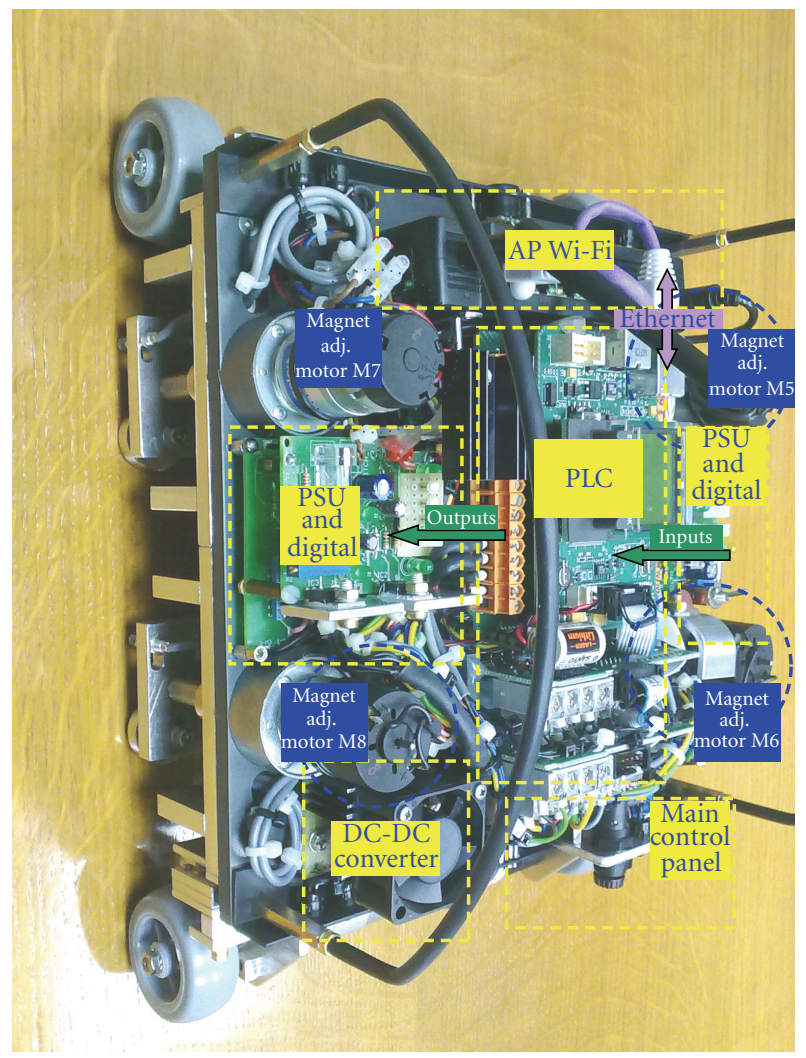

FIGURE 9: View from the top plane of the climbing robot.

This system allows to set the rotation direction and the start of each motor in an individual and independent way.

Regarding the Locomotion Unit control logic electronic circuit, the operating principle is similar to what was described for the control of the Adhesion Unit, with some minor differences that are associated with the particularities of this Unit [34].

5.3. DC Power Circuits. The Adhesion and the Locomotion Units have each a DC power supply circuit associated [34]. The DC Power Supply is implemented based on monolithic type regulators. The climbing vehicle possesses two of these circuits. One of them is used to provide the $5 \mathrm{~V}$ DC that powers all the digital circuits and $2 \times 12 \mathrm{~V} \mathrm{DC}$ for each pair of motors of the Locomotion Unit. The other circuit is used to provide the $5 \mathrm{~V}$ DC that powers the access point (AP) WiFi 802.11g (the system for the remote communication with the robot), and $2 \times 12 \mathrm{~V} \mathrm{DC}$ for each pair of motors of the Adhesion Unit.

The remaining electronic circuitry, such as the PLC and the whole set of sensors (except for the sonars, in the front and rear of the robot, used to detect obstacles, that are $5 \mathrm{~V}$ DC powered by the digital part), are powered directly from the $24 \mathrm{~V} \mathrm{DC}$ supply. Therefore, there is a system of power distribution at the $24 \mathrm{~V} \mathrm{DC}$ voltage level.

The Main Power Control Panel allows to power the entire mobile robot, and presents the future possibility of integration with batteries and their electrical charging circuit.

There is also, integrated into the power supply system, a DC-DC conversion unit (DC-to-DC converter). Its function is to dissipate as heat, through a controlled fan, the excess of power delivered from the $24 \mathrm{~V}$ DC supply, given the lower voltages also needed, such as $5 \mathrm{~V}$ DC and $12 \mathrm{~V} \mathrm{DC}$. The DC$\mathrm{DC}$ converter is powered from the $24 \mathrm{~V} \mathrm{DC}$ (Main Power) and provides two distinct voltage levels at its output. One, of $9 \mathrm{~V} \mathrm{DC}$, used to supply the monolithic type circuit that provides $5 \mathrm{~V} \mathrm{DC} / 700 \mathrm{~mA}$ to the AP Wi-Fi communication system. The other, of $12 \mathrm{~V} \mathrm{DC}$, supplies the monolithic circuit that provides $5 \mathrm{~V} \mathrm{DC} / 200 \mathrm{~mA}$ to all logic/digital circuits complementary to the PLC logical operation.

5.4. Electrical Layout. Figures 9 and 10 show the adopted electrical layout and a subtitled description of their functions and interconnections, namely, on the top and bottom surfaces of the climbing robot.

5.4.1. View from the Top Plane. It should be noted in Figure 9 the Ethernet connection between the Wi-Fi access point and the PLC, that will allow to program and control the entire vehicle.

5.4.2. View from Lower Plane. The main aspect that is depicted in Figure 10 is all sensory components that allow 


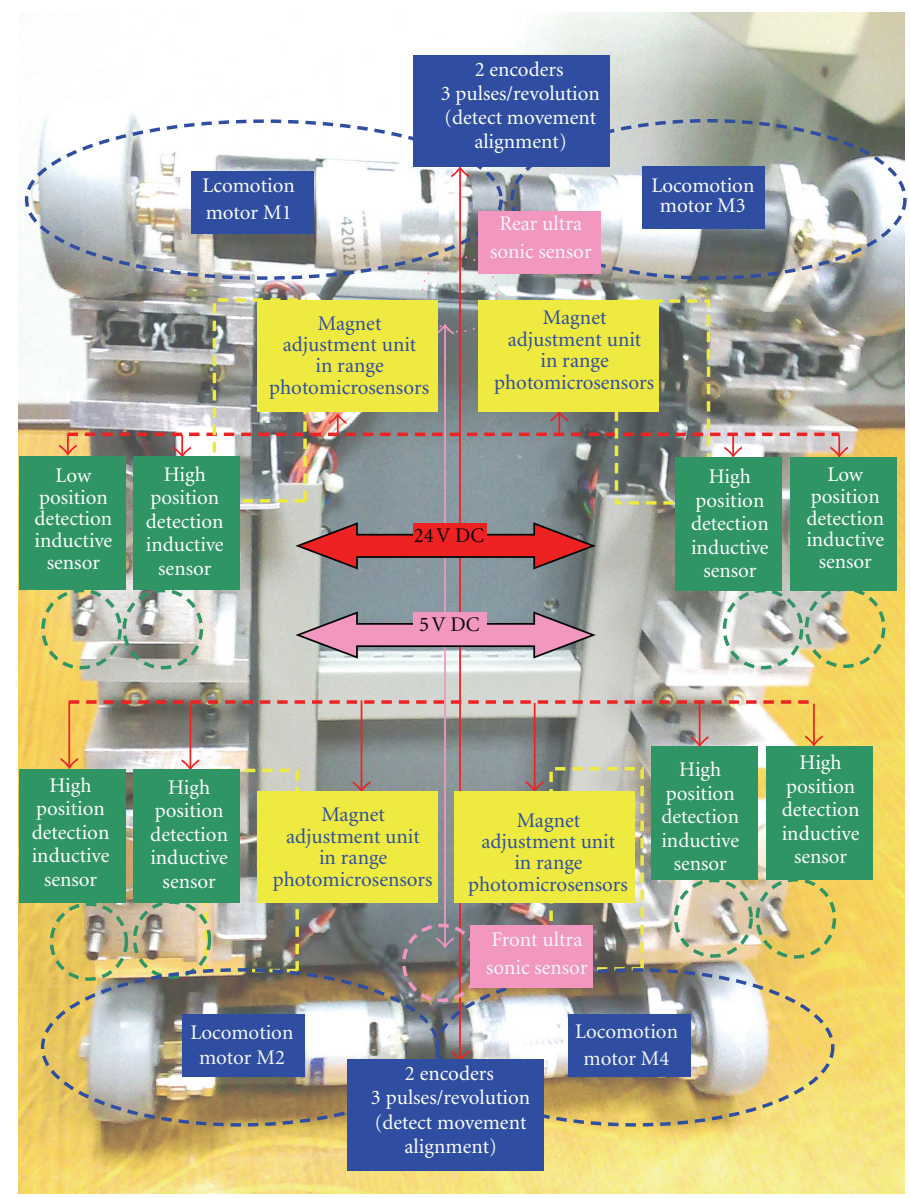

Figure 10: View from lower plane of the climbing robot.

the robot PLC to obtain feedback from the actions and mechanical interaction of the vehicle with the environment.

\section{Programming of the Control System}

6.1. PLC Program. The control program adopted for the vehicle operation is implemented on the PLC, in the Ladder programming language, with the aid of the RSLOGIX 500 programming software proprietary of Rockwell Automation. The PLC program takes into account the characteristics of the MicroLogix 1100 PLC used in the prototype. In its implementation was essential to handle, in an organized way, the data records that exist by default (default data files), with the aim of obtaining a structured programming. These records are for use as Tags throughout the program developed for the PLC [35].

In this program was established a main routine and four subroutines. In this case, the main program (main routine) is associated with LAD 2, and the remaining LAD (LAD 3, LAD 4, LAD 5, and LAD 6) are called by the main routine. The reason associated with this structure is related with the logic function assigned to each routine [35].
Besides calling the other routines, the main routine (LAD 2 ) is responsible for some initialization logic of the robot and for the main control over the locomotion and adhesion systems. It is also responsible for handling the logic required to connect the external logic circuits to the PLC, allowing an interface with the motors through the binary counters (74HCT4516 IC) and the H bridges (L293D IC).

The LAD 3 routine implements the logic required to configure and manually control (by a robot operator) the locomotion and adhesion systems.

Routine LAD 4 has all the logic needed to automatically control the adhesion and locomotion systems of the robot, without requiring any operator intervention. It is this routine that controls the magnets position regarding to the robot locomotion surface and handles the possibility of autonomous surface exploitation by the robot.

The LAD 5 routine processes the signals received from the sensors, in particular as regards the sonars for obstacle detection, and the motors rotational asymmetry detected by the encoders.

Finally, LAD 6 is associated with the logic control of a local physical manual control interface (Figure 11), constituted by two pressure switches, which are coupled to two digital inputs in the PLC. This interface allows to act on 


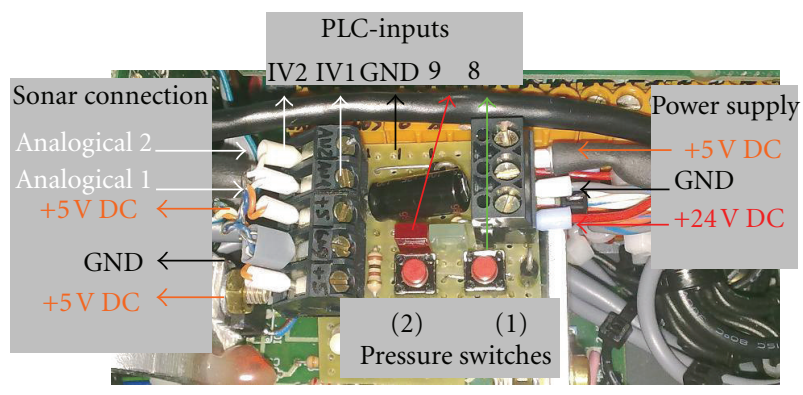

Figure 11: Local physical manual command interface over the adhesion and locomotion systems.

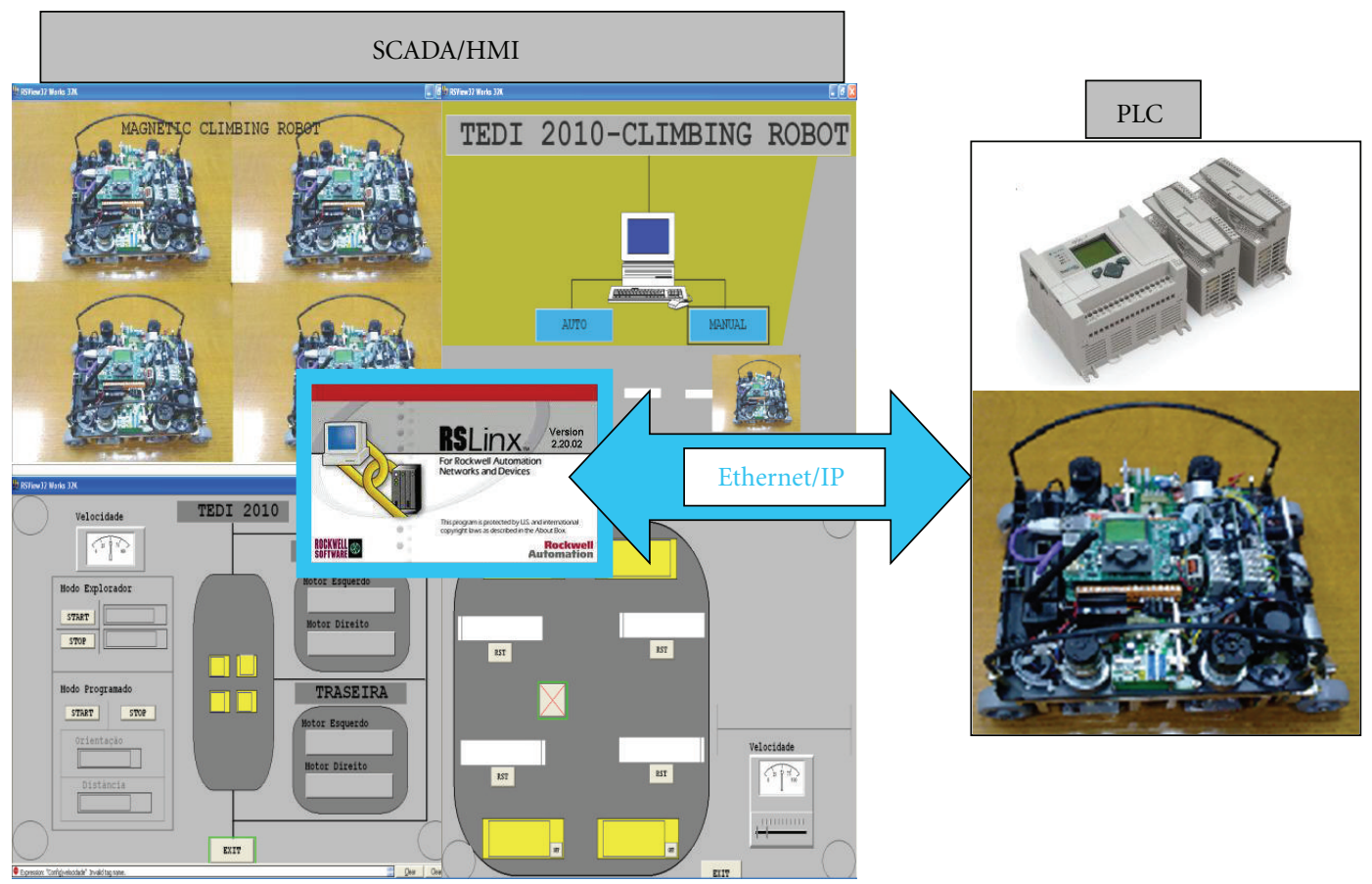

FIgURE 12: Prototype climbing robot supervision (SCADA-RSView32), from a remote computer.

the adhesion and locomotion systems, enabling some local features, such as:

(1) activation of the adhesion system;

(2) displacement of the four adhesion units towards the locomotion surface;

(3) stop the adhesion and locomotion systems;

(4) move the four adhesion units to the security zone, that is, in a direction opposite to the locomotion surface.

As can be identified in Figure 11, the local physical manual command interface is also used for the connection of the front and rear robot sonars to the $+5 \mathrm{~V}$ DC power supply and to the IV1 and IV2 PLC analog inputs.

\section{Human-Machine Interface}

In order to have a more friendly graphical environment for those who remotely operate the climbing robot, a software application was developed and is used as a human machine interface (HMI). This HMI application is of the Supervision Control and Data Acquisition (SCADA) type. The used software is the RSView32 (from Rockwell Automation), which provides greater ease of manipulation of the variables defined in the program that runs on the MicroLogix 1100 PLC. Figure 12 shows a picture illustrating the graphical environment of the prototype command interface, and its connection to the PLC.

It is possible to access all the configuration parameters of the adopted adhesion and locomotion processes, and have feedback from the physical variables measured by the climbing robot sensors, from any computer running this SCADA, and the dedicated programming associated, with its HMI directed towards the remote operation of the robot. 


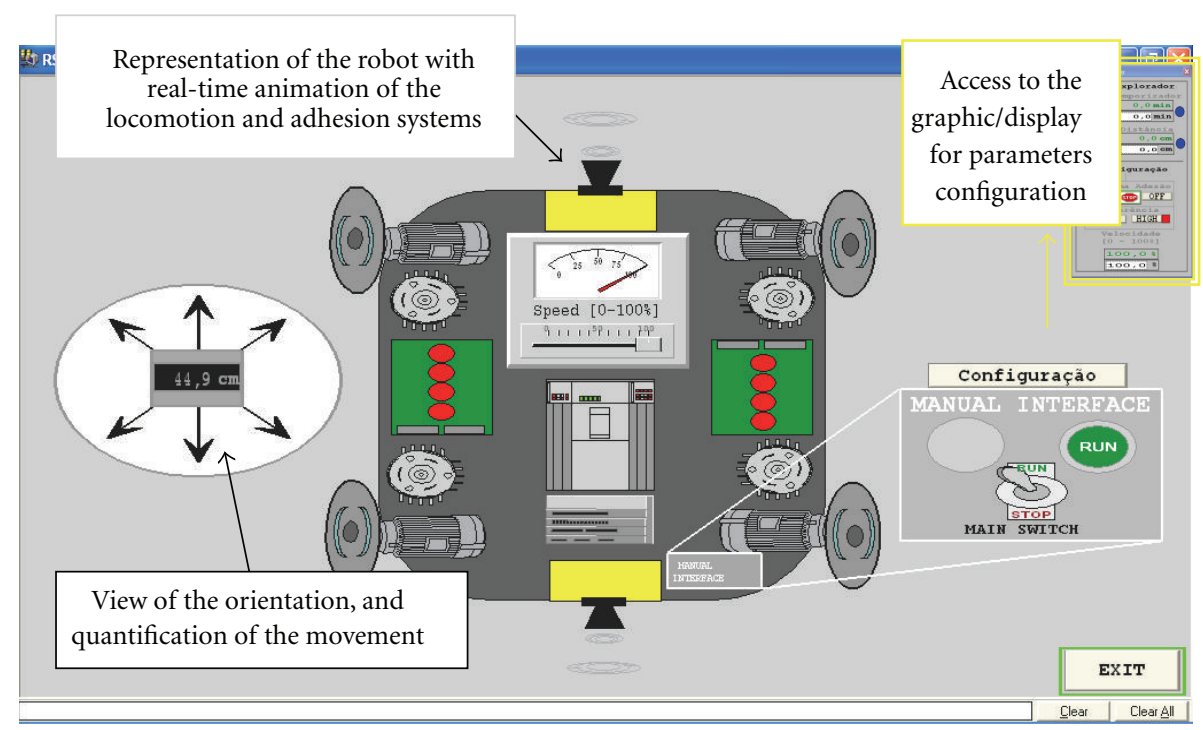

FIGURE 13: Picture of the graphic/display “Auto.”

In developing the SCADA/HMI program, were created and programmed seven graphs whose general function is associated with the remote control of the climbing robot [35]. The characteristics of each chart and its particular function are described below.

(1) The graphic/display "General", which is the HMI display screen.

(2) The graphic/display "Choice", which is the "gateway" to the other graphics/displays.

(3) The graphic/display "Alarms Register" allows the operator to view the list of active alarms and the occurrences $\log$ file, besides allowing to act on its recognition, activation, or deactivation.

(4) The graphic/display "Auto" is responsible for monitoring the remote operation capability of the vehicle, on automatic mode, while exploring the surrounding environment. Figure 13 describes this control.

(5) The graphic/display "CFG General" is used to configure some parameters related to the functioning of the robot.

(6) The graphic/display "Manual Adhesion" allows to manually operate the various features of the climbing robot that constitute the adhesion system.

(7) The graphic/display "Manual Locomotion" allows to manually operate the various features of the climbing robot integrating the locomotion system (Figure 14).

Concerning the option "Manual Locomotion" (see Figure 14), it is important to mention the possibility of manually controlling each movement in all directions. This possibility is allowed by the direction keys [35].

To assist the manual remote control of the robot locomotion, it is shown in the graphic/display "Manual Locomotion" the estimated travelled distance (in centimeters) by each wheel, allowing to identify asymmetries in the movement. There is also an indication of the distance (in centimeters) to any obstacles that are on the front or rear of the robot. When the obstacle is within the preset distance to the robot it stops, unless this option is disabled [35].

With all these graphics/displays, provided by the remote monitoring system of the robot (its HMI), it is possible for an operator to have "access" to all equipment placed on board the autonomous climbing robot. This allows the internal and external monitoring of the mobile system, and to operate the various features available in a controlled manner.

\section{Experimental Results}

The climbing robot, whose development is described in this paper, was the target of an initial study that focused on the best way to implement its mechanical structure (crucial to the operational success).

The robot mechanical structure would have to be structurally rigid, and the total backlash would have to be less than the desired accuracy of the adhesion units, particularly to control the distance of the magnets to the surface of mobility on the order of $1 \mathrm{~mm}$. Thus, it was adopted a lightweight, but structurally with low deflection, base structure (built from $8 \mathrm{~mm}$ thick PVC), reinforced with the top-to-top assembly of the Adhesion/Locomotion Units (that were accurately machined) over this base. This way a low deformation of the structure, when faced with the magnetic forces generated towards the surface of locomotion, has been achieved.

However, despite this careful implementation technique, a problem arose associated with a small backlash in the shafts of the locomotion motors. This backlash, comparatively to the precision required for the controlled adhesion, is somewhat critical and causes some problems during the robot movement, including the possibility of contact between the permanent magnets with the ferromagnetic surface. Thus, as a way of overcoming this situation, it is necessary to adopt 


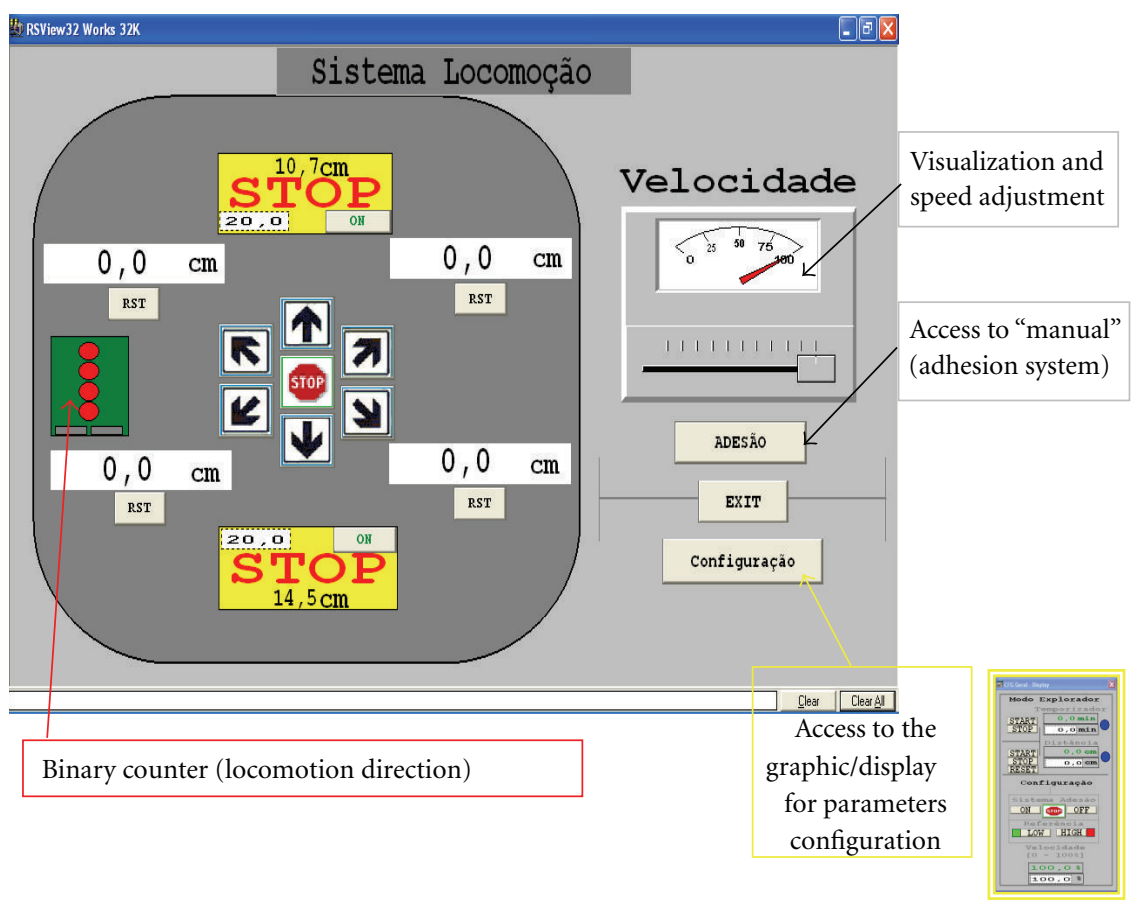

FIgURe 14: Picture of the graphic/display "Manual Locomotion.”

a very strict control criterion for maintaining the distance between the magnets to the surface, working with distances slightly greater than ideally possible and minimizing the response time of the Adhesion unit, in view of the demands of the system.

After concluding the development of the climbing robot, the prototype was subjected to several locomotion and adhesion tests.

During the tests performed on vertical surfaces, there were identified two major problems for a successful displacement of the robot in any desired direction, and whose resolution presents some difficulty.

The first problem is intrinsically linked to the mass of the final prototype (approximately $5 \mathrm{~kg}$ ), which forced the use of permanent magnets with approximately $108 \mathrm{~N}$ of force generated while in direct contact with the ferromagnetic surface, and a curve of force versus distance inversely proportional to the distance (on a roughly logarithmic form). These magnets, under certain conditions of approximation to the surface, cause the surface deformation towards the source of the force generated, providing many times an unwanted direct contact, due to the created friction.

The second identified problem is quite limiting of a smooth motion of the prototype, because it is related with the ability of the wheels to adhere to the surface for implementing the locomotion, when it presents little roughness (even presenting a polished appearance). Under these circumstances, given the ratio of the prototype weight, compensated for the achieved adhesion, with the wheels adhesion to the locomotion surface (direct relationship, in which more weight means greater adherence), the robot may have great difficulty in moving vertically. To minimize these problems it is necessary to test several modifications to the wheels (using a different type of rubber, making the surface rougher, etc.), to increase its adherence and, as already stated above, adopting a very strict control criterion to maintain the distance of the magnets to the surface, in order to keep under control the effects of the surface structural deformation. It is, nevertheless, necessary to consider that any action on the wheels, to change the adherence, may have effects on the maneuverability, because the robot has four fixed wheels and changes direction by the opposite rotation of the wheels on opposite sides.

It can also be useful to test the use of more "powerful" magnets which, although seeming a contradiction to what has been stated previously, would allow the adhesion units to work at a greater distance from the displacement surface, developing an equal, or even higher, adhesion force. In this situation, in case of surface deformation, the possibility of contact would be smaller, and the adherence could be improved due to a major "squeeze" of the wheels against the surface.

As part of the mechanical adjustments to be made in the prototype, it is necessary to pay special attention to the adjustment of the rotating magnets (mounted in parallel with the locomotion wheels), the inductive sensors for monitoring the adherence and to the photomicrosensors used for detection of the vertical position of the Adhesion System.

The rotating magnets have to be adjusted so as not to hamper the full contact of the rubber wheels with the surface (even with a slight deformation), in order to obtain the maximum possible adhesion by the materials in contact. 
The inductive sensors have to be adjusted relative to each other, and both in relation to the magnet, to comply with the adjustment process programmed for the Adhesion Unit.

The photomicrosensors, since they are a guarantee to avoid structural damage to the Adhesion unit, have to be positionally tuned to prevent the drive shaft to move the coupled structure off the limits of the mechanical security zone.

The electrical/electronic component used a mix of commercial equipment, such as the PLC and the expansion cards, and other equipment developed entirely by the authors (from their electric design to the execution of the PCB and the electronic assembly), such as the power sources and logic/digital circuits.

All the sensory parts were also selected to address the desired application and purchased commercially. Here, there were two major problems. The first is related with the sonar performance. Contrary to the specification, they present a weak opening and a low selectivity in detecting obstacles, not detecting those that are more distant from the center or the ones with a smaller size. The other problem is related to the design adopted for the motors control, including the ones from the Adhesion unit. Due to constraints associated with the limited number of I/Os provided by the PLC and expansion cards, a series implementation was adopted in controlling the direction of rotation of the motors, as opposed to the most common alternative (in parallel). Thus, the used outputs were rationalized, but the response speed and simplicity of control was sacrificed. In the particular situation of the response speed, this may present some obstacles to achieve a control criterion as effective as possible, for keeping the optimum distance of the magnets to the surface of locomotion, given the tolerances inherent to the actual mechanics and motors used.

The PLC programming took into account the functional requirements defined initially for the climbing robot, which are accessible in a friendly way via the HMI. However, there was a problem that is directly related to the number of fast counters available for this PLC model (just one counter). As there are four encoders (connected to common counters), that at the maximum associated motor speed generate impulses at a frequency of around $338.6 \mathrm{~Hz}$ (one pulse every $3 \mathrm{~ms}$ ), and considering the cycle time of the PLC program (which is around $10 \mathrm{~ms}$ ), there is loss of some pulses on each rotation of the gearmotor. Therefore, the value of the travelled distance cannot be obtained directly from the encoders, being, alternatively, calculated from the direct relationship between the number of pulses detected by the PLC for a unit of length. Since there are some minor fluctuations in the PLC cycle times, a small error is thus introduced in calculating the travelled distance with the use of the above indicated procedure. The solution would be to implement four real time counters, which later would provide the read values to the PLC.

From the overall results obtained, it can be concluded that these were very positive, since the approach to the dynamic positioning of the permanent magnets over the surface of locomotion, is quite promising in terms of results. However, special attention is needed to the final weight of the robot, because it could jeopardize its ability to adhere to the surface and lead to the surface deformation due to excessive adhesion force to maintain the adherence. Another aspect to improve is the way as the change of direction is implemented. This should be less dependent on the frictional characteristics of the surface, as this creates a problem of balance in relation to adherence. The ideal would be the Locomotion System having directional wheel(s) with associated direction change.

In conclusion, a possible miniaturization of the prototype, with a substantial reduction of its weight (without losing the technical offer in terms of processing and communications), associated with some minor modifications, particularly in the case of the change in direction, would lead to a high mobility climbing robot in any ferromagnetic structure and a good antifall safety, providing an excellent efficiency for carrying out the required tasks.

The prospects for future developments in this prototype are very encouraging, because there is a very broad and simplified room for maneuver. In terms of mechanical structure, it is perfectly possible to implement and test new systems, because the structural platform is quite flexible. At the programming level, it is easily possible to test new algorithms and control schemes for the adhesion and locomotion systems. The use of an industrial type PLC allows having a set of tools designed for simple and efficient use, even in more complex scenarios. The use of a communication network such as Ethernet allows to integrate a range of equipment from third parties, geared towards the development of the prototype itself, or other (precision instruments), to allow the climbing robot hired inspection, besides allowing the robot integration in a more global communication infrastructure, such as the Internet.

It is thus quite possible to control this robot remotely, from anywhere in the world via the worldwide public network (the Internet) using, for example, a Virtual Private Network (VPN) type of connection.

\section{Conclusions}

Considering the severity of many environments where there is the need for human labor, the use of climbing robots in these applications presents a broad perspective. The main applications envisaged for these machines range from cleaning to inspection of difficult to reach man made constructions.

Up to now, considerable research has been devoted to these machines, and more than 200 prototypes for these applications have been developed worldwide by the year 2006 [10]. However, the practical application of climbing robots is still limited. Apart from a small set of successful manufactured products (being the success measure a relative one), most are just prototypes and few of them can be found in normal use, due to its poor performance during on site testing.

To make climbing robots a popular substitute for manual labor, are prerequisites a high reliability and high efficiency and, moreover, at an affordable price $[13,36,37]$. Meeting 
these demands is still far, which indicates that there is still a long road of development and improvement to go $[2,38-40]$.

Given these considerations, this paper presented the development of a climbing robot, namely its mechanical and electrical construction, the control architecture and the HMI for its control. This vehicle presents wheeled locomotion, while the adhesion is implemented through permanent magnets, and is intended to be used in the inspection of different types of ferromagnetic structures. The distinguishing characteristic of this machine is its dynamic adjustment system of the permanent magnets in order to assure the machine adhesion to the surfaces, even when crossing irregular and curved surfaces.

The robot structure (both mechanical and electrical) is now complete, as well as the programming of its control system. Several tests have confirmed the adequacy of the vehicle to the intended application, while manually and remotely controlled, verifying its adequacy to the locomotion in ferromagnetic vertical surfaces with irregularities and curvatures, while in autonomous mode.

\section{Acknowledgments}

The authors would like to acknowledge FCT, FEDER, POCTI, POSI, POCI, POSC, and COMPETE for their support to R\&D Projects and GECAD.

\section{References}

[1] M. F. Silva and J. A. T. Machado, "A survey of technologies for climbing robots adhesion to surfaces," in Proceedings of the IEEE International Conference on Computational Cybernetics (ICCC '08), pp. 127-132, Stara Lesna, Slovakia, November 2008.

[2] M. A. Armada and P. G. de Santos, "Perspectives of climbing and walking robots for the construction industry," in Proceedings of the 4th International Conference on Climbing and Walking Robots and the Support Technologies for Mobile Machines (CLAWAR '01), K. Berns and R. Dillmann, Eds., pp. 929-936, Professional Engineering, Karlsruhe, Germany, September 2001.

[3] F. Weise, J. Kohnen, H. Wiggenhauser, C. Hillenbrand, and K. Berns, "Non-destructive sensors for inspection of concrete structures with a climbing robot," in Proceedings of the 4th International Conference on Climbing and Walking Robots and the Support Technologies for Mobile Machines (CLAWAR '01), K. Berns and R. Dillmann, Eds., pp. 945-952, Professional Engineering, Karlsruhe, Germany, September 2001.

[4] T. P. Sattar, Z. Zhao, J. Feng, B. Bridge, S. Mondal, and S. Chen, "Internal in-service inspection of the floor and walls of oil, petroleum, and chemical storage tanks with a mobile robot," in Proceedings of the 5th International Conference on Climbing and Walking Robots and the Support Technologies for Mobile Machines (CLAWAR '02), P. Bidaud and F. B. Amar, Eds., pp. 947-954, Professional Engineering, Paris, France, September 2002.

[5] M. Elliot, W. Morris, and J. Xiao, "City-climber: a new generation of wall-climbing robots," in Proceedings of the IEEE International Conference on Robotics and Automation, pp. 4413-4415, Orlando, Fla, USA, May 2006.
[6] T. P. Sattar, B. Bridge, S. Chen, and Z. Zhao, "Development of clawar systems that combine the tasks of monitoring, mobility, manipulation, and measurement for industrial inspection tasks," in Proceedings of the 6th International Conference on Climbing and Walking Robots and the Support Technologies for Mobile Machines (CLAWAR '03), G. Muscato and D. Longo, Eds., pp. 699-706, Professional Engineering, Catania, Italy, September 2003.

[7] K. Berns, C. Hillenbrand, and T. Luksch, "Climbing robots for commercial applications-a survey," in Proceedings of the 6th International Conference on Climbing and Walking Robots and the Support Technologies for Mobile Machines (CLAWAR '03), G. Muscato and D. Longo, Eds., pp. 771-776, Catania, Italy, September 2003.

[8] C. Balaguer, A. Gimenez, and A. Jordon, "Climbing robots' mobility for inspection and maintenance of 3D complex environments," Autonomous Robots, vol. 18, no. 2, pp. 157169, 2005.

[9] A. Nishi, "A wall climbing robot using propulsive force of propeller," in Proceedings of the 5th International Conference on Advanced Robotics, pp. 320-325, Pisa, Italy, June 1991.

[10] S. Chen, J. Shang, Z. Zhao, T. Sattar, and B. Bridge, "Novel solutions to design problems of industrial climbing robots," in Climbing and Walking Robots, M. O. Tokhi, G. S. Virk, and M. A. Hossain, Eds., pp. 139-146, Springer, 2006.

[11] F. IFF, Fraunhofer iff-siriusc facade cleaning robot, 2010, http://publica.fraunhofer.de/dokumente/N-170630.html.

[12] ROBOSOFT, Glass roof cleaning-customised automatic glass-roof cleaning robots, 2011, http://www.robosoft.com/ eng/sous_categorie.php?id=1017.

[13] R. D. Schraft, F. Simons, T. Schafer, W. Keil, and S. Anderson, "Concept of a low-cost, window-cleaning robot," in Proceedings of the 6th International Conference on Climbing and Walking Robots and the Support Technologies for Mobile Machines (CLAWAR '03), G. Muscato and D. Longo, Eds., pp. 785-792, Professional Engineering, Catania, Italy, September 2003.

[14] A. Degani, A. Shapiro, H. Choset, and M. T. Mason, "A dynamic single actuator vertical climbing robot," in Proceedings of the IEEE/RSJ International Conference on Intelligent Robots and Systems (IROS '07), pp. 2901-2906, IEEE, San Diego, Calif, USA, November 2007.

[15] D. Longo and G. Muscato, "Advances in mobile robotics: state of the art and experimental considerations," in Advances in Mobile Robotics, L. Marques, A. de Almeida, M. O. Tokhi, and G. S. Virk, Eds., pp. 6-28, World Scientific, 2008.

[16] W. Yan, L. Shuliang, X. Dianguo, Z. Yanzheng, S. Hao, and G. Xueshan, "Development \& application of wall-climbing robots," in Proceedings of the IEEE International Conference on Robotics and Automation (ICRA '99), pp. 1207-1212, Detroit, Mich, USA, May 1999.

[17] T. Akinfiev and M. A. Armada, "On the optimal location of a magnet gripper for a climbing robot," in Proceedings of the 4th International Conference on Climbing and Walking Robots and the Support Technologies for Mobile Machines (CLAWAR '01), K. Berns and R. Dillmann, Eds., pp. 877-882, Professional Engineering, Karlsruhe, Germany, September 2001.

[18] S. Mondal, T. P. Sattar, and B. Bridge, "Tofd inspection of v-groove butt welds on the hull of a container ship with a magnetically adhering wall climbing robot," in Proceedings of the 5th International Conference on Climbing and Walking Robots and the Support Technologies for Mobile Machines (CLAWAR '02), P. Bidaud and F. B. Amar, Eds., pp. 955-961, Professional Engineering, Paris, France, September 2002. 
[19] D. Longo and G. Muscato, "Design of a climbing robot for wall exploration-a neural network approach for pressure control onboard the alicia ii prototype," in Proceedings of the 5th International Conference on Climbing and Walking Robots and the Support Technologies for Mobile Machines (CLAWAR '02), P. Bidaud and F. B. Amar, Eds., pp. 1021-1028, Professional Engineering, Paris, France, September 2002.

[20] D. Bozzetti, F. Chignoli, T. Cola, E. D’Alessio, and M. Gori, "Robotized system for visual inspection inside boiler chambers and no-contact thickness evaluation of waterwall tubes in the steam generators of thermoelectric plants," in Proceedings of the 6th International Conference on Climbing and Walking Robots and the Support Technologies for Mobile Machines (CLAWAR '03), G. Muscato and D. Longo, Eds., pp. 753-760, Professional Engineering, Catania, Italy, September 2003.

[21] R. Alexander, T. S. White, G. Callow, D. Gough, and J. Anderson, "A mobile climbing robot for high-precision manufacture and inspection of aero-structures," in Proceedings of the 6th International Conference on Climbing and Walking Robots and the Support Technologies for Mobile Machines (CLAWAR '03), G. Muscato and D. Longo, Eds., pp. 777-784, Professional Engineering, Catania, Italy, September 2003.

[22] S. Park, H. D. Jeong, and Z. S. Lim, "Design of a mobile robot system for automatic integrity evaluation of large size reservoirs and pipelines in industrial fields," in Proceedings of the IEEE/RSJ International Conference on Intelligent Robots and Systems (IROS '03), pp. 2618-2623, Las Vegas, Nev, USA, October 2003.

[23] X. Gao and K. Kikuchi, "Study on a kind of wall cleaning robot," in Proceedings of the IEEE International Conference on Robotics and Biomimetics (IEEE ROBIO '04), pp. 391-394, August 2004.

[24] D. Longo and G. Muscato, "Design of a single sliding suction cup robot for inspection of non porous vertical wall," in Proceedings of the 35th International Symposium on Robotics, pp. 1153-1161, Paris, France, March 2004.

[25] J. Sanchez, F. Vazquez, and E. Paz, "Machine vision guidance system for a modular climbing robot used in shipbuilding," in Climbing and Walking Robots, M. O. Tokhi, G. S. Virk, and M. A. Hossain, Eds., pp. 893-900, Springer, 2006.

[26] H. Hosokai and F. Hara, "Manoeuvrability passing over obstacles on a pipeline by a pipeline inspection," in Proceedings of the 4th International Conference on Climbing and Walking Robots and the Support Technologies for Mobile Machines (CLAWAR '01), K. Berns and R. Dillmann, Eds., pp. 883-889, Professional Engineering, Karlsruhe, Germany, September 2001.

[27] K. Berns, T. Braun, C. Hillenbrand, and T. Luksch, "Developing climbing robots for education," in Climbing and Walking Robots, M. A. Armada and P. G. de Santos, Eds., pp. 981-988, Springer, 2005.

[28] M. Prieto, M. Uquillas, and M. Armada, "Compliance torque control of a multi-legged climbing robot," in Proceedings of the 4th International Conference on Climbing and Walking Robots and the Support Technologies for Mobile Machines (CLAWAR '01), K. Berns and R. Dillmann, Eds., pp. 891-898, Professional Engineering, Karlsruhe, Germany, September 2001.

[29] B. E. Shores and M. A. Minor, "Design, kinematic analysis, and quasi-steady control of a morphic rolling disk biped climbing robot," in Proceedings of the IEEE International Conference on
Robotics and Automation, pp. 2732-2737, Barcelona, Spain, April 2005.

[30] M. A. Armada, P. G. de Santos, V. Garcia, M. Prieto, and S. Nabulsi, "Design of mobile robots," in Proceedings of the International Conference on Climbing and Walking Robots and the Support Technologies for Mobile Machines (CLAWAR '05), pp. 2890-2895, London, UK, September 2005.

[31] L. P. Kalra and J. Gu, "An autonomous self contained wall climbing robot for nondestructive inspection of aboveground storage tanks," in Proceedings of the 9th International Conference on Climbing and Walking Robots and the Support Technologies for Mobile Machines (CLAWAR '06), pp. 183-188, Brussels, Belgium, September 2006.

[32] W. Fischer, F. Tache, and R. Siegwart, "Inspection system for very thin and fragile surfaces, based on a pair of wall climbing robots with magnetic wheels," in Proceedings of the IEEE/RSJ International Conference on Intelligent Robots and Systems (IROS '07), pp. 1216-1221, IEEE, San Diego, Calif, USA, October 2007.

[33] A. L. C. Oliveira, M. F. Silva, and R. S. Barbosa, "Development of an wheeled climbing robot for metallic surfaces with permanent magnetic system dynamic adjustment," in Emerging Trends in Mobile Robotics, H. Fujimoto, M. O. Tokhi, H. Mochiyama, and G. S. Virk, Eds., pp. 1340-1346, World Scientific, Nagoya, Japan, 2010.

[34] A. L. C. Oliveira, M. F. Silva, and R. S. Barbosa, "Architecture of an wheeled climbing robot with dynamic adjustment of the adhesion system," in Proceedings of the 8th IEEE International Symposium on Intelligent Systems and Informatics (SISY '10), pp. 127-132, Subotica, Serbia, September 2010.

[35] A. L. C. Oliveira, M. F. Silva, and R. S. Barbosa, "Humanmachine interface for the control of a climbing robot," in Proceedings of the 31st IASTED International Conference on Modelling, Identification and Control (MIC '11), pp. 254-261, Innsbruck, Austria, February 2011.

[36] G. L. Rosa and R. Sinatra, "Design of an end-effector of a climbing robot for vertical surfaces," in Proceedings of the 6th International Conference on Climbing and Walking Robots and the Support Technologies for Mobile Machines (CLAWAR '03), G. Muscato and D. Longo, Eds., pp. 793-800, Catania, Italy, September 2003.

[37] H. A. Warren, "Economic prospects for mobile robots a clawar perspective-work package 6 (wp6) year 1, may 2003," in Proceedings of the 6th International Conference on Climbing and Walking Robots and the Support Technologies for Mobile Machines (CLAWAR '03), G. Muscato and D. Longo, Eds., pp. 1057-1070, Professional Engineering, Catania, Italy, September 2003.

[38] H. A. Warren, "Clawar task 19-barriers to commercial exploitation of mobile robotics," in Proceedings of the 5th International Conference on Climbing and Walking Robots and the Support Technologies for Mobile Machines (CLAWAR '02), P. Bidaud and F. B. Amar, Eds., pp. 917-930, Professional Engineering, Paris, France, September 2002.

[39] A. Semerano, R. Hasselvander, M. P. Ribeiro, and G. S. Virk, "Clawar r\&d project clustering," in Proceedings of the 6th International Conference on Climbing and Walking Robots and the Support Technologies for Mobile Machines (CLAWAR '03), G. Muscato and D. Longo, Eds., pp. 1043-1048, Professional Engineering, Catania, Italy, September 2003.

[40] G. S. Virk, "Clawar modularity-the guiding principles," in Proceedings of the 6th International Conference on Climbing and Walking Robots and the Support Technologies for Mobile 
Machines (CLAWAR '03), G. Muscato and D. Longo, Eds., pp. 1025-1031, Professional Engineering, Catania, Italy, September 2003. 

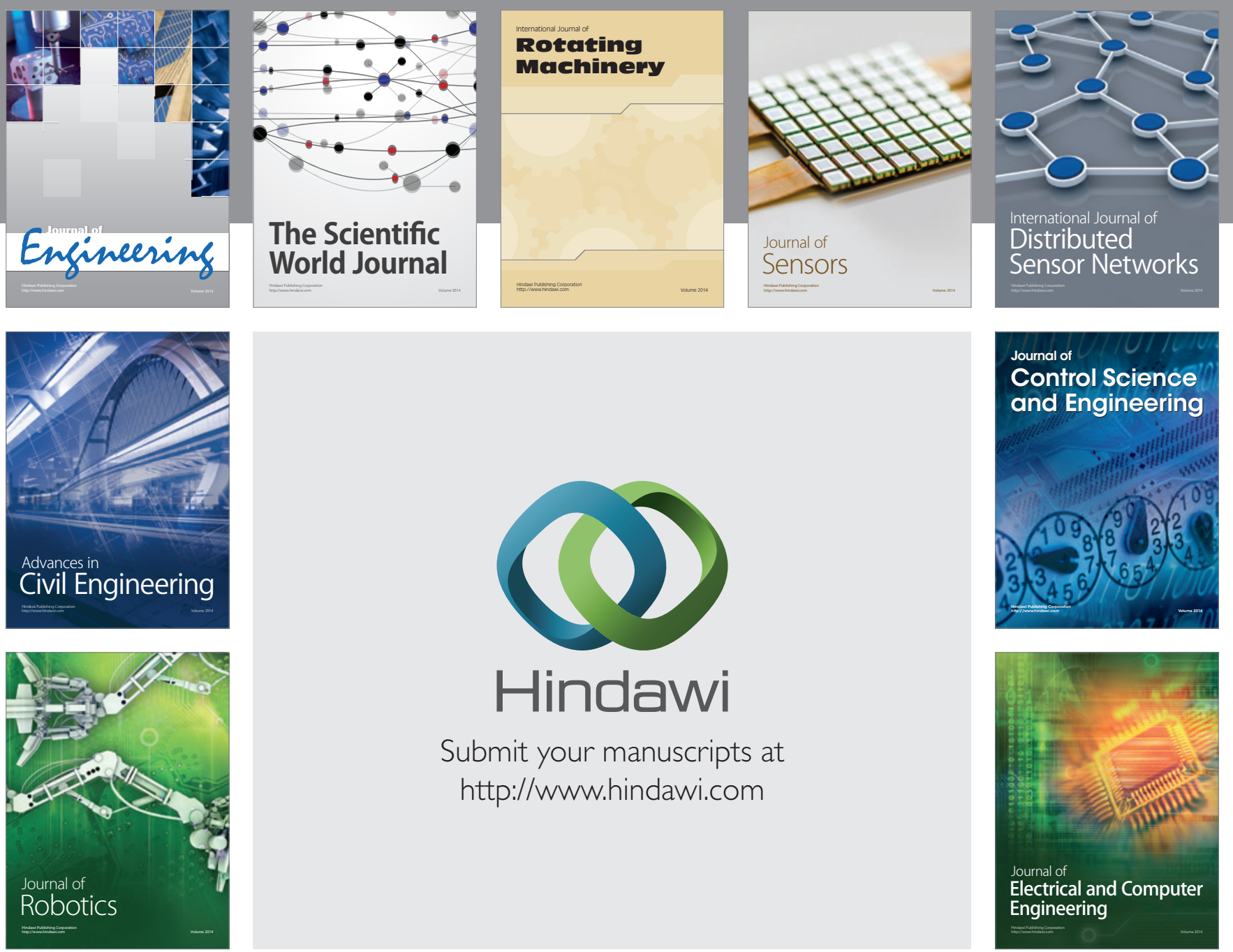

Submit your manuscripts at

http://www.hindawi.com
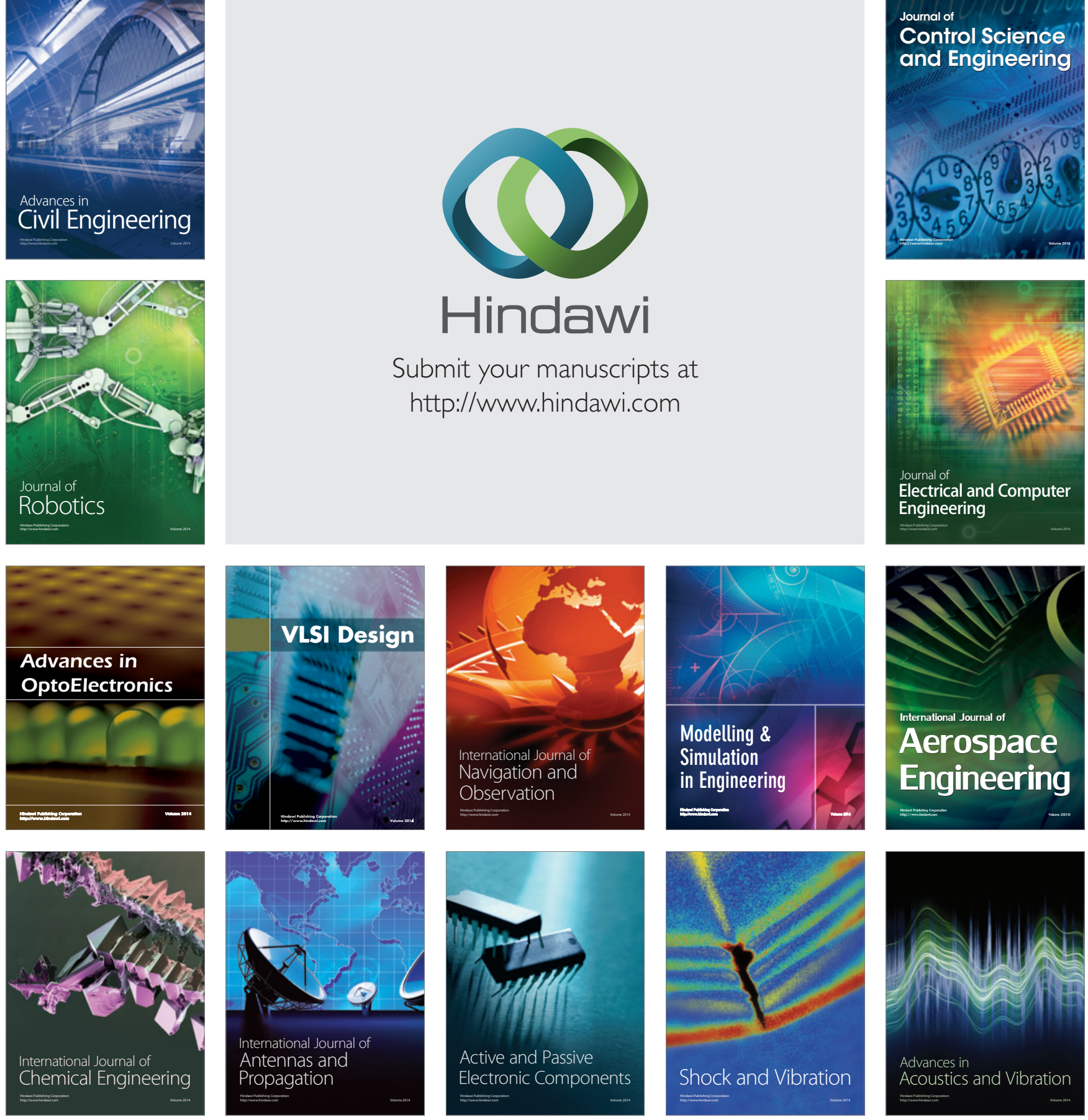